\title{
Snake venom metalloproteinases and disintegrins: interactions with cells
}

A.S. Kamiguti'

M. Zuzel ${ }^{1}$ and

R.D.G. Theakston ${ }^{2}$

\author{
${ }^{1}$ Department of Haematology, Royal Liverpool University Hospital, \\ University of Liverpool, Liverpool, UK \\ ${ }^{2}$ Alistair Reid Venom Research Unit, Liverpool School of Tropical Medicine, \\ Liverpool, UK
}

\section{Correspondence \\ A.S. Kamiguti \\ Department of Haematology \\ Royal Liverpool University Hospital \\ Prescot Street \\ Liverpool L69 3BX \\ UK \\ Fax: 00441517064311 \\ E-mail:aurakami@liverpool.ac.uk

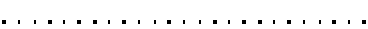

Received February 13, 1998 Accepted March 16, 1998

\section{Abstract}

Metalloproteinases and disintegrins are important components of most viperid and crotalid venoms. Large metalloproteinases referred to as MDC enzymes are composed of an $\mathrm{N}$-terminal Metalloproteinase domain, a Disintegrin-like domain and a Cys-rich C-terminus. In contrast, disintegrins are small non-enzymatic RGD-containing cysteine-rich polypeptides. However, the disintegrin region of MDC enzymes bears a high degree of structural homology to that of the disintegrins, although it lacks the RGD motif. Despite these differences, both components share the property of being able to recognize integrin cell surface receptors and thereby to inhibit integrin-dependent cell reactions. Recently, several membrane-bound MDC enzymes, closely related to soluble venom MDC enzymes, have been described in mammalian cells. This group of membrane-anchored mammalian enzymes is also called the ADAM family of proteins due to the

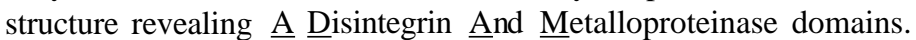
ADAMs are involved in the shedding of molecules from the cell surface, a property which is also shared by some venom MDC enzymes.

\section{Introduction}

Venoms of viperid and crotalid snakes are rich sources of components that can affect hemostasis by causing changes in blood coagulation and platelet function. Venom components affecting the clotting system include thrombin-like enzymes (TLE) which convert fibrinogen to fibrin, and activators of prothrombin, factor $\mathrm{V}$ and factor $\mathrm{X}$. Platelet function can be affected by venom components such as hemorrhagic metalloproteinases, phospholipases and RGD-containing disintegrins. As a result, it is common to find
Key words

- Venom

- Metalloproteinase

- Disintegrin

- Platelet

- Integrin

- Signaling consumption of clotting factors and blood incoagulability accompanied by hemorrhage in victims of snakebite. Various reviews on this subject have been published (1-4).

Several venom enzymes lacking coagulant activity but possessing the ability to cause local hemorrhage have been characterized, as recently reviewed by Bjarnason and Fox (5). They are zinc-containing metalloproteinases varying in size from 20 to 100 $\mathrm{kDa}$, capable of inducing rapid local bleeding. Metalloproteinases of different sizes are often present in the same venom. The high molecular weight enzymes are classified as 
metalloproteinase/disintegrin-like/cysteinerich (MDC) proteins, according to a structure containing an $\mathrm{N}$-terminal catalytic site, a disintegrin-like domain followed by a cysteine-rich C-terminus. These enzymes have a potent proteolytic effect on the extracellular matrix proteins. Their effects on the blood vessel wall components have been extensively studied $(5,6)$. The arrest of bleeding from the damaged blood vessels, however, depends on normal function of blood platelets and clotting factors, which are the principal blood components involved in hemostasis. The extent to which these latter components are directly affected by venom hemorrhagic metalloproteinases has not been explored in detail.

Another group of snake venom components that affect platelet function is comprised of small non-enzyme polypeptides (5$10 \mathrm{kDa}$ ) called disintegrins. Disintegrins have also been recently investigated in many other cells besides platelets. Since disintegrin domains of venom MDC enzymes and disintegrins show pronounced structural homology, they will be reviewed together here, referring particularly to their effects on cellcell interactions using platelets as a model.

\section{Mechanism of hemostasis}

Blood fluidity in the circulation is maintained by the non-thrombogenic properties of the intact blood vessel walls. Damage to blood vessels triggers a prompt response of hemostatic reactions to prevent hemorrhage (7). Very briefly, these reactions include contraction of the vessel wall itself due to the action of released vasoactive agents, adhesion and aggregation of circulating platelets to form a hemostatic plug and activation of clotting factors leading to the formation of fibrin clots. In order to allow full tissue healing, the clots are subsequently removed by the fibrinolytic enzyme, plasmin. In situations where any component of these mechanisms is altered, hemostasis is compromised and the result could be either thrombosis or hemorrhage (bleeding due to platelet and/or clotting factor deficiencies).

In small blood vessels, platelets alone can arrest bleeding. In their inactive form, platelets are discoid but once activated they become round, extend numerous pseudopods and then aggregate. This occurs when platelets are exposed to ADP, thrombin, adrenaline, collagen, and other agonists. Each agonist stimulates platelets via a specific receptor, whereby the receptor for collagen belongs to the superfamily of $\alpha \beta$ dimeric proteins or integrins (8). Indeed, the first reaction of platelets to vessel damage is their adhesion to the adhesive proteins, von Willebrand factor (vWF) and collagen on the exposed subendothelium. The respective platelet receptors for these proteins are the glycoprotein (gp) Ib/IX complex $(9,10)$ and $\alpha_{2} \beta_{1}$ integrin also known as the gpIa/IIa complex (11). Engagement of these receptors stimulates platelets to secrete their granular contents and in particular ADP, which promotes activation of platelet $\alpha_{\mathrm{II}} \beta_{3}$ integrin or gpIIb/IIIa. This receptor then binds the RGDcontaining ligands (fibrinogen and von Willebrand factor) and thereby promotes platelet aggregation, resulting in the formation of a platelet plug which stops bleeding. Thus, the mechanism by which platelets act clearly depends on their surface receptors for vessel wall and plasma proteins and on normal content and release of their granular ADP stores.

\section{Venom metalloproteinase/disintegrin- like/cysteine-rich enzymes}

\section{Mechanism of hemorrhage by venom MDC enzymes}

As mentioned above, the presence of clotting factor activators in many venoms frequently causes consumption coagulopathy in envenomed victims and this is often associated with systemic bleeding. In some 
envenomed patients, systemic bleeding can be fatal $(12,13)$ and, interestingly in one case, fatal intracranial hemorrhage has been described apparently in the absence of coagulopathy (14). Moreover, there have been other reports describing spontaneous systemic bleeding following snake bite in which no coagulation defects have been recorded $(12,15,16)$. Systemic bleeding without coagulopathy has also been reported in a case of envenoming by the snake Philodryas olfersii (17), which led to the discovery of one hemorrhagic metalloproteinase in the venom of this species (18). Experimental studies have shown that venoms of various snakes can cause pronounced local hemorrhage in the absence of coagulant activity $(15,19)$. In one such study using a purified non-coagulant hemorrhagic toxin, systemic bleeding was observed (20), whereas in another, using a different hemorrhagic toxin, this effect could not be demonstrated (21). Therefore, different metalloproteinases appear to differ in their ability to cause systemic effects; this clearly requires further indepth studies of the effects of these enzymes on the hemostatic mechanism.

Various studies have demonstrated that purified venom metalloproteinases alone cause local hemorrhage. Hemorrhagic metalloproteinases from crotalid and viperid venoms produce local bleeding by causing lesions in the walls of small blood vessels $(22,23)$. It is believed that this is caused by proteolysis of components of the basal lamina of the microvasculature (24-26). In animal experiments, such disruption of microvessels becomes evident within minutes of an intradermal injection of venom metalloproteinases. These enzymes degrade all major proteins of the extracellular matrix (ECM) $(6,27,28)$ and in this respect they resemble the cell-secreted soluble matrix metalloproteinases (MMP). A positive correlation exists between the proteolytic activity of venom metalloproteinases and their hemorrhagic potencies. Larger enzymes are more potent than the smaller ones in degrading the extracellular matrix $(6,26)$. However, the proteolytic attack of these enzymes on ECM proteins is slow, while the in vivo hemorrhagic effect of the venom occurs within minutes of the bite or experimental injection. This indicates that the mechanism of action of these enzymes may be considerably more complex $(23,29)$. It has been well documented that the venom hemorrhagic metalloproteinases, because of their broad substrate specificity, cause digestion of the extracellular matrix proteins and damage the integrity of blood vessels. Although this can explain the phenomenon of local bleeding, past studies have shed little light on the possibility that metalloproteinases can have effects on other components of the hemostatic mechanism and thereby also contribute to systemic bleeding.

We have investigated the effects of envenoming by Bothrops jararaca, because this species constitutes the major problem in southeastern Brazil, and because local and systemic hemorrhage is one of the most prominent results of envenoming by this species (30-32). The main venom component responsible for this effect is thought to be jararhagin (33), an MDC enzyme which causes intense local hemorrhage, inhibits platelet aggregation in vitro and, as shown in animal experiments, also contributes to systemic bleeding (34). The reason why jararhagin contributes significantly to the systemic bleeding is because this enzyme is not effectively inhibited by plasma proteinase inhibitors (34). When radiolabelled jararhagin was incubated with whole plasma and its binding to plasma proteins examined by immunoelectrophoresis, only $\alpha_{2}$-macroglobulin $\left(\alpha_{2}-\mathrm{M}\right)$ was capable of binding jararhagin. However, jararhagin retained considerable proteolytic activity towards high molecular weight substrates such as fibrinogen and hide powder azure in the presence of a large molar excess of $\alpha_{2}$-M (34). Others have also shown that some venom metallo- 
proteinases are not completely inhibited by equimolar amounts of $\alpha_{2}-\mathrm{M}(28,35)$, but the precise reason why the inhibitor-enzyme reaction failed to proceed to completion was not clarified.

Of all venom components known to interfere with hemostasis, the hemorrhagic metalloproteinases have been the least investigated. Little attention has been paid to the effects of these enzymes on platelets which, as mentioned before, play a central role in the hemostatic mechanism.

\section{Venom MDC enzymes and platelet function}

Earlier studies of venom metalloproteinases showed that they can inhibit platelet aggregation in vitro (36). As the majority of these enzymes are also known to hydrolyze the $\alpha$-chain of fibrinogen ( $\alpha$-fibrinogenases; 37 ), and since fibrinogen is an important cofactor in platelet aggregation $(38,39)$, it has been proposed that the inhibition of platelet aggregation caused by these enzymes is due to degradation of fibrinogen $(2,40)$. However, we have shown that the proteolysis by jararhagin of the C-terminal fibrinogen $\alpha$ chain, which contains an RGD sequence, does not affect fibrinogen-dependent platelet aggregation (41). This is mainly because jararhagin and other venom $\alpha$-fibrinogenases do not attack the fibrinogen $\gamma$-chain, which contains the more important platelet binding site.

The venom MDC enzymes, such as jararhagin, have a disintegrin-like domain whose function is not precisely known. However, we have reported that this domain may play an important role in the substrate specificity of the enzyme $(42,43)$. Jararhagin has a very selective effect on platelets in plateletrich plasma in vitro with inhibition of both collagen- and ristocetin-induced cell aggregation only. This suggested either the proteolysis by jararhagin of collagen and vWF, or an interference with their respective platelet receptors, $\alpha_{2} \beta_{1}$ integrin and gpIb. The fibrillar type I collagen currently used in platelet aggregation studies is not degraded by venom MDC enzymes, the preferential substrate structure being type IV collagen (5).

In jararhagin-treated platelets, no alterations of gpIb could be detected either by flow cytometry or by immunoprecipitation (44). This indicated that jararhagin inhibition of platelet responses to the ristocetin/ vWF complex may have been due to some effect on the multimeric plasma protein, $\mathrm{vWF}$. The 225-kDa vWF subunit contains the $\mathrm{Val}^{449}$-Lys ${ }^{728} \mathrm{~N}$-terminal domain responsible for ristocetin-induced binding to platelet gpIb, and one binding site for platelet $\alpha_{\mathrm{IIb}} \beta_{3}$ integrin containing the C-terminal RGDS ${ }^{1744-1747}$ sequence (45). We have shown that the treatment of vWF with jararhagin resulted in the proteolysis of vWF subunits in the N-terminal half of the molecule which contains the platelet gpIb binding site (44). Thus, jararhagin inhibited platelet responses to ristocetin by cleaving the ligand vWF, with loss of the gpIb binding site.

There are several proposed platelet collagen receptors including $\alpha_{2} \beta_{1}$ and $\alpha_{\mathrm{IIb}} \beta_{3}$ integrins, gpIV and gpVI. It is proposed that collagen first binds to the I domain of the $\alpha_{2} \beta_{1}$ integrin; this binding generates signals for the activation and expression of a binding site on $\alpha_{\mathrm{II}} \beta_{3}$ integrin (46) resulting in collagen binding, presumably by the collagen RGD sequence. These reactions result in a full platelet aggregation response. The $\alpha_{\mathrm{IIb}} \beta_{3}$ integrin has also been found to be both structurally and functionally unaltered in jararhagin-treated platelets (41). This was expected from the preserved fibrinogen-dependent platelet aggregation which is mediated by the $\alpha_{\mathrm{IIb}} \beta_{3}$ integrin. GpIV is also functional in jararhagin-treated platelets (Kamiguti AS and Zuzel M, unpublished data). In contrast, the expression of the $\alpha_{2} \beta_{1}$ integrin following platelet treatment by jararhagin is markedly reduced and we found that this was due to the proteolysis of the $\beta_{1}$ subunit of this integrin (42). There is evi- 
dence that the proteolysis of the platelet $\alpha_{2} \beta_{1}$ integrin by jararhagin is a two-step process in which jararhagin first recognizes the $\alpha_{2}$ I domain (47) and subsequently cleaves the $\beta_{1}$ subunit (42). Jararhagin, as an intact enzyme, does not remain bound to platelets. This can be explained by the alteration of the integrin structure following proteolysis which results in the loss of both collagen and jararhagin binding (42). An equilibrium binding could be demonstrated when the enzyme was inactivated by treatment with 1,10-phenanthroline (42). Therefore, it is most likely that the recognition of the platelet $\alpha_{2} \beta_{1}$ integrin by jararhagin occurs via the disintegrinlike domain including the Cys-rich region. Furthermore, by using synthetic ECD-containing peptides based on the disintegrinlike domain of jararhagin, we showed that these peptides effectively inhibited platelet responses to collagen, thus confirming the importance of this domain in cell recognition (43).

Platelet interaction with collagen results in increased protein tyrosine phosphorylation, one of the earliest signals being the phosphorylation of the non-receptor $72-\mathrm{kDa}$ tyrosine kinase Syk or pp $72^{\text {syk }}(48,49)$. The activation of pp72 $2^{\text {syk }}$ depends on both $\alpha_{2} \beta_{1}$ integrin and $\mathrm{gpVI}$ because the absence of either one of these receptors results in decreased Syk phosphorylation and a poor platelet response to fibrillar collagen (50-53). We found that the proteolysis of the $\alpha_{2} \beta_{1}$ integrin by jararhagin inhibited protein tyrosine phosphorylation in collagen-stimulated platelets, with greatly reduced tyrosine phosphorylation of $p p 72^{\text {syk }}$ (54). These findings not only explain the altered responses of jararhagintreated platelets to collagen, but also support the hypothesis that $\alpha_{2} \beta_{1}$ integrin plays a vital role in the platelet/collagen interaction (55, 56). Moreover, since congenital deficiency of this receptor leads to bleeding manifestations (52), it is reasonable to expect that jararhagin-treated platelets would not be hemostatically fully competent.

\section{Venom disintegrins}

Disintegrins are cysteine-rich low molecular weight polypeptides, which contain an RGD sequence recognized by integrins. Trigramin, from the venom of Trimeresurus gramineus, was the first venom disintegrin characterized as a competitive inhibitor of fibrinogen binding to the $\alpha_{\mathrm{II}} \beta_{3}$ integrin of platelets activated by ADP (57). Following this, a number of other disintegrins isolated from different snake venoms have been reported and reviewed (58). It is interesting that, unlike other RGD-containing ligands (i.e. fibrinogen), venom disintegrins bind to $\alpha_{I I b} \beta_{3}$ integrin without requiring prior activation of this integrin. This is because disintegrins have a unique RGD-containing loop which can express the ligand-induced binding site (LIBS) on the $\beta_{3}$ subunit (59).

Recently, a relatively large disintegrin $(28 \mathrm{kDa})$ containing an ECD sequence instead of RGD, isolated from the venom of $B$. jararaca has been reported. This disintegrin has exactly the same primary structure as the disintegrin-like domain of jararhagin and was therefore named jararhagin C (60). Unlike jararhagin, which in our studies showed no interference with platelet response to ADP, jararhagin $\mathrm{C}$ inhibited both the ADP- and collagen-induced responses of platelets. $\mathrm{Nev}$ ertheless, the finding that jararhagin $\mathrm{C}$ inhibits collagen-induced platelet aggregation confirms our conclusion that the disintegrin-like domain of the enzyme jararhagin recognizes the platelet collagen receptor, $\alpha_{2} \beta_{1}$ integrin.

\section{Effects of venom disintegrin on cell function}

As mentioned above, disintegrins have the ability to inhibit the binding of RGDcontaining ligands to platelet $\alpha_{\mathrm{II}} \beta_{3}$ integrin and, because of this, they impair platelet aggregation responses dependent on this receptor. Thus, platelets treated with disintegrins do not aggregate in response to collagen stimulation. However, these platelets 
show normal phosphorylation of the tyrosine kinase pp72 ${ }^{\text {syk }}(54,61)$. As mentioned above, collagen first binds to the $\alpha_{2} \beta_{1}$ integrin, signaling for $\mathrm{pp} 72^{\mathrm{syk}}$ phosphorylation and an inside-out activation of $\alpha_{\mathrm{II}} \beta_{3}$ integrin. In the disintegrin-treated platelets, the $\alpha_{\mathrm{II}} \beta_{3}$ integrin is already occupied by the venom ligand so that the aggregation response is lost. However, pp72 $7{ }^{\text {syk }}$ phosphorylation is preserved, confirming that free $\alpha_{2} \beta_{1}$ can bind collagen and signals in these platelets. In this respect, we found results using both jararhagin and contortrostatin particularly revealing. Contortrostatin (62) is a dimeric RGD-containing disintegrin from Agkistrodon contortrix contortrix venom. Suboptimal ADP stimulation of jararhagin-treated platelets resulted in a full aggregation response to collagen and this could be inhibited by either RGDS peptide or contortrostatin (54). Our explanation for this is that ADP caused activation of the $\alpha_{\mathrm{II}} \beta_{3}$ integrin in these platelets, which then bound collagen. Inhibition of this binding by contortrostatin emphasizes the importance of $\alpha_{\mathrm{IIb}} \beta_{3}$ in addition to $\alpha_{2} \beta_{1}$ integrin in the platelet/collagen interaction.

Recently, disintegrins have been also shown to interfere with other integrin-mediated cell functions; for example, inhibition of tumor cell-extracellular matrix adhesion (63-65) and metastasis $(62,66)$, of adhesion of human umbilical vein endothelial cells to matrix proteins (59), and also of egg fertilization through inhibition of sperm-oolemmal adhesion (67).

\section{Venom MDC enzymes and disintegrins: structure/function relationships}

The elucidation of the primary structure of different members of the venom hemorrhagic metalloproteinase-disintegrin family $(33,68-70)$ has generated new interest in the function of these enzymes. Comparison of amino acid sequences have indicated that, despite differences in their molecular sizes, all these enzymes may be related through a common ancestral gene encoding a prodomain, metalloproteinase, disintegrin and cysteine-rich domains $(33,69,71)$. The prodomain contains a conserved sequence PRCGVPD, called a cysteine-switch, which is responsible for the enzyme activation and is lacking in the mature protein. A multidomain structure characterizes the large hemorrhagic metalloproteinases; the $\mathrm{N}$-terminal region possessing a zinc-containing metalloproteinase domain is followed by a disintegrin-like and a C-terminal cysteine-rich domain. Moreover, disintegrin-like regions of MDC enzymes possess a high sequence homology to the venom disintegrins. Disintegrins contain an RGD sequence, but a KGD sequence has also been reported (72). In contrast, the disintegrin-like regions of most venom MDC enzymes have a conserved ECD sequence overlapping the region where an RGD sequence occurs in the homologous disintegrins. However, this is not a constant motif found in all disintegrin-like domains because some venom MDC enzymes have a DCD sequence instead of ECD $(73,74)$.

Since the large hemorrhagic metalloproteinases possess a disintegrin-like domain (MDC enzymes) it is thought that some disintegrins may originate from autoproteolysis of these enzymes (75). The discovery that jararhagin $C$ is identical to the disintegrinlike plus Cys-rich regions of jararhagin in $B$. jararaca venom (60) supports this proposal.

\section{Membrane-anchored cell MDC enzymes (ADAM family proteins)}

A number of membrane-anchored MDC enzymes have been reported. They belong to the ADAM family proteins, with $\underline{A}$ Disintegrin And Metalloproteinase domain (76). They are unique cell surface proteins possessing both a potential adhesion domain as well as a potential protease domain, not related to other surface adhesion molecules and proteases, but rather to domains found in 
the snake venom MDC enzymes. Sequence homology to the disintegrin-like domain of venom hemorrhagic metalloproteinases has also been found in a sperm protein, fertilin $\beta$, which mediates egg binding in sperm-egg fusion (77). Recently, it has been shown that the disintegrin-like region of this sperm protein recognizes the $\alpha_{6} \beta_{1}$ integrin on the egg membrane (78). In addition, six other distinct ADAMs have been identified in spermatogenic cells; all are considered to be potential ligands for integrins on the cell surface or receptors for extracellular matrix and are, therefore, expected to play important roles in cell-cell and cell-matrix interactions (79).

The presence of ADAM proteins is not confined to reproductive tissue only. In 1989, a metalloproteinase isolated from bovine brain myelin membrane preparations appeared to be distinct from the other MMP described at that time (80). The determination of the primary structure of this metalloproteinase by cDNA cloning revealed that significant similarity exists between the deduced sequence of the bovine protein and jararhagin, the greatest homology being found in the disintegrin domain (81). Similar findings involve another ADAM protein, meltrin$\alpha$, which participates in myoblast fusion (82). More recently, a widely expressed cellular ADAM or MDC enzyme, designated as MDC9, has been described to have a cytoplasmic tail that can bind the $\mathrm{SH} 3$ domain of signal molecules of the Src family proteins, thus implicating MDC9 in interactions with the cytoskeleton or with intracellular signaling molecules (83).

The cytokine tumor-necrosis factor- $\alpha$ (TNF- $\alpha$ ) has physiological importance in inflammation. The release of soluble TNF- $\alpha$ from its membrane-bound precursor involves an ADAM enzyme called TNF- $\alpha$-converting enzyme (TACE), recently purified and cloned from monocytes (84). TACE has been shown to be present in monocytes, peripheral blood T cells, neutrophils, endothelial and smooth muscle cells. TACE has also been purified and cloned from porcine spleen and the recombinant protein shown to correctly process precursor TNF- $\alpha$ to the mature form (85). Thus, it appears that the membraneanchored ADAM proteins play an important function in shedding cell surface proteins (84). It is interesting that our investigations demonstrated that also the soluble venom MDC enzyme jararhagin can release TNF- $\alpha$ in a similar fashion to TACE (86). Thus, there is an indication that jararhagin may play a role in the inflammatory response evoked by $B$. jararaca venom, although this has not yet been fully investigated.

\section{Conclusions}

Venom disintegrins and MDC enzymes are excellent tools for investigating integrin cell receptor function. Interference with integrins and their ligands is the major mechanism by which these proteins contribute to the toxicity of snake venoms. Moreover, the understanding of the precise mechanism of action of these venom components and the finding of the minimum structure required for their action will certainly extend their application in studies of cell physiology. Thus, the studies of venom disintegrins and MDC enzymes have already greatly aided the advance which has been recently achieved in understanding the function of similar mammalian proteins. 


\section{References}

1. Seegers WH \& Ouyang C (1979). Snake venoms and blood coagulation. Handbook of Experimental Pharmacology, 52: 684750.

2. Ouyang C, Teng C-M \& Huang T-F (1992). Characterization of snake venom components acting on blood coagulation and platelet function. Toxicon, 30: 945-966.

3. Hutton RA \& Warrell DA (1993). Action of snake venom components on the haemostatic system. Blood Reviews, 7: 176-189.

4. Kamiguti AS \& Sano-Martins IS (1995). South American snake venoms affecting haemostasis. Journal of Toxicology, Toxin Reviews, 14: 359-374.

5. Bjarnason JB \& Fox JW (1994). Hemorrhagic metalloproteinases from snake venoms. Pharmacology and Therapeutics, 62: 325-372.

6. Bjarnason JB \& Fox JW (1988/89). Hemorrhagic toxins from snake venoms. Journal of Toxicology, Toxin Reviews, 7: 121209.

7. Bithell TC (1993). The physiology of primary haemostasis. In: Lee JR, Bithell TC, Foester J, Athens JW \& Lukens JN (Editors), Wintrobe's Clinical Hematology. Lea \& Febiger, London.

8. Hynes RO (1992). Integrins: versatility, modulation, and signaling in cell adhesion. Cell, 69: 11-25.

9. Baumgartner HR, Tschoop TB \& Weiss HJ (1978). Defective adhesion of platelets to subendothelium in von Willebrand's disease and Bernard Soulier syndrome. Thrombosis and Haemostasis, 39: 782-783.

10. Weiss HJ, Turitto VT \& Baumgartner HR (1986). Platelet adhesion and thrombus formation on subendothelium in platelets deficient in glycoproteins $\mathrm{Ilb}-\mathrm{IIla}$ and $\mathrm{Ib}$ and storage $\alpha$-granules. Blood, 67: 322330.

11. Santoro SA, Rajpara SM, Staatz WD \& Woods VL (1988). Isolation and characterization of a platelet surface collagen binding complex to VLA-2. Biochemical and Biophysical Research Communications, 153: 217-223.

12. Warrell DA, Ormerod LD \& Davidson NMcD (1975). Bites by puff-adder (Bitis arietans) in Nigeria, and value of antivenom. British Medical Journal, 20: 697-700.

13. Warrell DA, Davidson NMcD, Greenwood BM, Ormerod LD \& Prentice CRM (1977). Poisoning by bites of the saw-scaled or carpet viper (Echis carinatus) in Nigeria. Quarterly Journal of Medicine, 46: 33-62.
14. Kouyoumdjian JA, Polizelli C, Lobo SMA \& Guimarães SM (1991). Fatal extradural haematoma after snake bite (Bothrops moojeni). Transactions of the Royal Society of Tropical Medicine and Hygiene, 85: 552.

15. Gitter S \& de Vries A (1968). Symptomatology, pathology and treatment of bites by Near Eastern, European and North African snakes. In: Bucherl W, Buckley EE \& Deulofeu V (Editors), Venomous Animals and their Venoms. Academic Press, New York.

16. Kamiguti AS, Rugman FP, Theakston RDG, Franca FOS, Ishii H, Hay CRM \& Butantan Institute Antivenom Study Group (1992). The role of venom haemorrhagin in spontaneous bleeding in Bothrops jararaca envenoming. Thrombosis and Haemostasis, 67: 484-488.

17. Silva MV \& Buononato MA (1983/84). Relato clínico de envenenamento humano por Philodryas olfersii. Memórias do Instituto Butantan, 47/48: 121-126.

18. Assakura MT, Salomão MG, Puorto G \& Mandelbaum FR (1992). Hemorrhagic, fibrinogenolytic and edema-forming activities of the venom of the colubrid Philodryas olfersii (green snake). Toxicon, 30 : 427-437.

19. Theakston RDG \& Reid HA (1983). The development of simple standard assay procedures for the characterization of snake venoms. Bulletin of the World Health Organization, 61: 949-956.

20. Kamiguti AS, Theakston RDG, Desmond HP \& Hutton RA (1991). Systemic haemorrhage in rats induced by a haemorrhagic fraction from Bothrops jararaca venom. Toxicon, 29: 1097-1105.

21. Kornalik F (1992). Analysis of haemorrhagic diathesis (HD) and DIC due to snake venom enzymes on an experimental model. In: Gopalakrishnakone P \& Tan CK (Editors), Recent Advances in Venom Research. National University of Singapore, Singapore.

22. Ohsaka A (1979). Hemorrhagic, necrotizing and edema-forming effects of snake venoms. Handbook of Experimental Pharmacology, 52: 480-546.

23. Ownby CL (1990). Locally acting agents: myotoxins, hemorrhagic toxins and dermonecrotic factors. In: Shier WT \& Mebs D (Editors), Handbook of Toxicology. Marcel Dekker, New York.

24. Ohsaka A, Just M \& Habermann E (1973). Action of snake venom principles on isolated glomerular basement membrane.
Biochimica et Biophysica Acta, 323: 415-428.

25. Bjarnason JB \& Tu AT (1978). Hemorrhagic toxins from Western diamondback rattlesnake (Crotalus atrox) venom: isolation and characterization of five toxins and the role of zinc in hemorrhagic toxin e. Biochemistry, 17: 3395-3404.

26. Bjarnason JB, Hamilton D \& Fox JW (1988). Studies on the mechanism of hemorrhage production by five proteolytic toxins from Crotalus atrox venom. Biological Chemistry Hoppe-Seyler, 369: 121 129.

27. Baramova EN, Shannon JD, Bjarnason JB \& Fox JW (1989). Degradation of extracellular matrix proteins by haemorrhagic metalloproteinases. Archives of Biochemistry and Biophysics, 275: 63-71.

28. Baramova EN, Shannon JD, Bjarnason JB, Gonias SL \& Fox JW (1990). Interaction of hemorrhagic metalloproteinase with human $\alpha_{2}$-macroglobulin. Biochemistry, 29: 1069-1074.

29. Lomonte B (1994). Tissue damage and inflammation induced by snake venoms. $\mathrm{PhD}$ thesis, Goteberg University.

30. Rosenfeld G (1971). Symptomatology, pathology and treatment of snake bites in South America. In: Bucherl W, Buckley E \& Deulofeu V (Editors), Venomous Animals and their Venoms. Academic Press, New York.

31. Maruyama M, Kamiguti AS, Cardoso JLC, Sano-Martins IS, Chudzinski AM, Santoro ML, Morena P, Antonio LC, Mihara M \& Kelen EMA (1990). Studies on blood coagulation and fibrinolysis in patients bitten by Bothrops jararaca (Jararaca). Thrombosis and Haemostasis, 63: 449453.

32. Cardoso JLC, Fan HW, França FOS, Jorge MT, Leite RP, Nishioka SA, Avila A, SanoMartins IS, Santoro ML, Chudzinski AM, Castro SCB, Kamiguti AS, Kelen EMA, Hirata $\mathrm{MH}$, Mirandola RMS, Theakston RDG \& Warrell DA (1993). Randomized comparative trial of three antivenoms in the treatment of envenoming by lanceheaded vipers (Bothrops jararaca) in São Paulo, Brazil. Quarterly Journal of Medicine, 86: 315-325.

33. Paine M, Desmond HP, Theakston RDG \& Crampton JM (1992). Purification, cloning and molecular characterization of a high molecular weight hemorrhagic metalloproteinase, jararhagin, from Bothrops jararaca venom. Journal of Biological Chemistry, 267: 22869-22876. 
34. Kamiguti AS, Desmond HP, Theakston RDG, Hay CRM \& Zuzel M (1994). Ineffectiveness of the inhibition of the main haemorrhagic metalloproteinase from $\mathrm{Bo}$ throps jararaca venom by its only plasma inhibitor, $\alpha_{2}$-macroglobulin. Biochimica et Biophysica Acta, 1200: 307-314.

35. Pandya BV \& Budzynski AZ (1984). Anticoagulant proteases from Western diamondback rattlesnake (Crotalus atrox) venom. Biochemistry, 23: 460-467.

36. Ouyang C, Teng C-M \& Chen YC (1979). Properties of fibrinogen degradation products produced by $\alpha$ - and $\beta$-fibrinogenases of Trimeresurus mucrosquamatus snake venom. Toxicon, 17: 121-126.

37. Markland FS (1991). Inventory of $\alpha$ - and $\beta$ fibrinogenase from snake venoms. Thrombosis and Haemostasis, 65: 438443.

38. Hawiger J, Timmons S, Kloczewiak M, Strong DD \& Doolittle RF (1982). $\gamma$ and $\alpha$ chains of human fibrinogen possess sites reactive with human platelet receptors. Proceedings of the National Academy of Sciences, USA, 79: 2068-2071.

39. Plow EF, Srouji AH, Meyer D, Marguerie G \& Ginsberg MH (1984). Evidence that three adhesive proteins interact with a common recognition site on activated platelets. Journal of Biological Chemistry, 259: 5388-5391.

40. Teng C-M \& Huang T-F (1991). Inventory of exogenous inhibitors of platelet aggregation. Thrombosis and Haemostasis, 65: 624-626.

41. Kamiguti AS, Slupsky JR, Zuzel M \& Hay CRM (1994). Properties of fibrinogen cleaved by jararhagin, a metalloproteinase from the venom of Bothrops jararaca. Thrombosis and Haemostasis, 72: 244249.

42. Kamiguti AS, Hay CRM \& Zuzel M (1996). Inhibition of collagen-induced platelet aggregation as the result of cleavage of $\alpha_{2} \beta_{1}$ integrin by the snake venom metalloproteinase jararhagin. Biochemical Journal, 320: 635-641.

43. Kamiguti AS, Moura-da-Silva AM, Laing GD, Knapp T, Zuzel M, Crampton JM \& Theakston RDG (1997). Collagen-induced secretion-dependent phase of platelet aggregation is inhibited by the snake venom metalloproteinase jararhagin. Biochimica et Biophysica Acta, 1335: 209-217.

44. Kamiguti AS, Hay CRM, Theakston RDG \& Zuzel M (1995). Insights into the mechanism of haemorrhage caused by snake venom metalloproteinases. Toxicon, 34: 627-642.

45. Titani K, Kumar S, Takio K, Ericsson LH,
Wade RD, Ashida K, Walsh KA, Chopek MW, Sadler JE \& Fujiwara K (1986). Amino acid sequence of human von Willebrand factor. Biochemistry, 25: 31713184.

46. Shattil SJ (1995). Function and regulation of the $B_{3}$ integrins in hemostasis and vascular biology. Thrombosis and Haemostasis, 74: 149-155.

47. De Luca M, Ward CM, Ohmori K, Andrews RK \& Berndt M (1995). Jararhagin and jaracetin: novel snake venom inhibitors of the integrin collagen receptor, $\alpha_{2} \beta_{1}$. Biochemical and Biophysical Research Communications, 206: 570576.

48. Taniguchi T, Kitagawa H, Yasue S, Yanagi S, Sakai K, Asahi M, Ohta S, Takeuchi F, Nakamura S \& Yamamura H (1993). Protein tyrosine kinase $p 72^{\text {syk }}$ is activated by thrombin and is negatively regulated through $\mathrm{Ca}^{2+}$ mobilization in platelets. Journal of Biological Chemistry, 268: 2277-2279.

49. Fuji C, Yanagi S, Sada K, Nagai K, Taniguchi T \& Yamamura H (1994). Involvement of protein-tyrosine kinase p72syk in collagen-induced signal transduction in platelets. European Journal of Biochemistry, 226: 243-248.

50. Sugiyama $T$, Okuma M, Ushikubi $F$, Sensaki S, Kanaji K \& Uchino H (1987). A novel platelet aggregating factor found in a patient with defective collagen-induced platelet aggregation and autoimmune thrombocytopenia. Blood, 69: 1712-1720.

51. Ichinobe T, Takayama H, Ezumi Y, Yanagi S, Yamamura H \& Okuma M (1995). Cyclic AMP-insensitive activation of c-Src and Syk protein-tyrosine kinase through platelet membrane glycoprotein VI. Journal of Biological Chemistry, 270: 2802928036.

52. Nieuwenhuis HK, Akkerman JWM, Houdijk WPM \& Sixma JJ (1985). Human blood platelets showing no response to collagen fail to express surface glycoprotein la. Nature, 318: 470-472.

53. Asazuma N, Yatomi Y, Ozaki Y, Qi R, Kuroda K, Satoh K \& Kume S (1996). Protein-tyrosine phosphorylation and $p 72^{\text {syk }}$ activation in human platelets stimulated with collagen is dependent upon glycoprotein la/lla and actin polymerization. Thrombosis and Haemostasis, 75: 648654.

54. Kamiguti AS, Markland FS, Zhou Q, Laing GD, Theakston RDG \& Zuzel M (1997). Proteolytic cleavage of the $B_{1}$ subunit of platelet $\alpha_{2} \beta_{1}$ integrin by the metalloproteinase jararhagin compromises collagen- stimulated phosphorylation of pp72 ${ }^{\text {syk }}$. Journal of Biological Chemistry, 272: 32599-32605.

55. Santoro SA (1986). Identification of a 160,000 dalton platelet membrane protein that mediates the initial divalent cation-dependent adhesion of platelets to collagen. Cell, 46: 913-920.

56. Staatz WD, Rajpara SM, Wayner EA, Carter WG \& Santoro SA (1989). The membrane glycoprotein la-Ila (VLA2) complex mediates the $\mathrm{Mg}^{++}$-dependent adhesion of platelets to collagen. Journal of Cell Biology, 108: 1917-1924.

57. Huang T-F, Holt JC, Lukasiewcz H \& Niewiarowski S (1987). Trigramin. A low molecular weight peptide inhibiting fibrinogen interaction with platelet receptors expressed on glycoprotein IIb/IIla complex. Journal of Biological Chemistry, 262: 16157-16163.

58. Niewiarowski S, MacLane MA Klocsewiak M \& Stewart GJ (1994). Disintegrins and other naturally occurring antagonists of platelet fibrinogen receptor. Seminars in Hematology, 31: 289-300.

59. Juliano $D$, Wang $Y$, Marcinkiewcz $C$, Rosenthal LA, Stewart GJ \& Niewiarowski $S$ (1996). Disintegrin interaction with $\alpha_{v} B_{3}$ integrin on human umbilical vein endothelial cells: expression of ligand-induced binding site on $B_{3}$ subunit. Experimental Cell Research, 225: 132-142.

60. Usami Y, Fujimura $\mathrm{Y}$, Miura $\mathrm{S}$, Shima $\mathrm{H}$, Yoshida E, Yoshioka A, Hirano K, Suzuki M \& Titani K (1994). A 28 kDa-protein with disintegrin-like structure (jararhagin-C) purified from Bothrops jararaca venom inhibits collagen- and ADP-induced platelet aggregation. Biochemical and Biophysical Research Communications, 201: 331-339.

61. Clark EA, Trikha M, Markland FS \& Brugge JS (1994). Structurally distinct disintegrins contortrostatin and multisquamatin differentially regulate platelet tyrosine phosphorylation. Journal of Biological Chemistry, 269: 21940-21943.

62. Trikha $M$, De Clerck $Y$ \& Markland FS (1994). Contortrostatin, a snake venom disintegrin, inhibits $B_{1}$ integrin-mediated human metastatic melanoma cell adhesion and blocks experimental matastasis. Cancer Research, 54: 4993-4998.

63. Knudsen KA, Tuszynski GP, Huang T-F \& Niewiarowski S (1988). Trigramin, an RGD-containing peptide from snake venom, inhibits cell-substratum adhesion of human melanoma cells. Experimental Cell Research, 179: 42-49.

64. Sheu JR, Lin CH \& Huang T-F (1994). Triflavin, an antiplatelet peptide, inhibits 
tumor cell-extracellular matrix through an arginine-glycine-aspartic acid-dependent mechanism. Journal of Laboratory and Clinical Medicine, 123: 256-263.

65. Beviglia L, Stewart GJ \& Niewiarowski S (1995). Effect of four disintegrins on the adhesive and metastatic properties of B16F10 melanoma cells in a murine model. Oncology Research, 7: 7-20.

66. Morris VL, Schmidt EE, Koop S, MacDonald IC, Grattan M, Khokha MA, MacLane MA, Niewiarowski S, Chambers AF \& Groom AC (1995). Effects of the disintegrin eritostatin on individual steps of hematogenous metastasis. Experimental Cell Research, 219: 571-578.

67. Bronson RA, Gailit J, Bronson S \& Oula L (1995). Echistatin, a disintegrin, inhibits sperm-oolemmal adhesion but not oocyte penetration. Fertility and Sterility, 64: 414420.

68. Takeya H, Oda K, Miyata T, Omori-Satoh T \& Iwanaga S (1990). The complete amino acid sequence of high molecular mass hemorrhagic protein HR1B isolated from the venom of Trimeresurus flavoviridis. Journal of Biological Chemistry, 265: 16068-16073.

69. Hite LA, Shannon JD, Bjarnason JB \& Fox JW (1992). Sequence of a cDNA clone encoding the zinc metalloproteinase hemorrhagic toxin e from Crotalus atrox: evidence for signal, zymogen, and disintegrin-like structures. Biochemistry, 31: 6203-6211.

70. Kini R \& Evans HJ (1992). Structural domains in venom proteins: evidence that metalloproteinases and nonenzymatic platelet aggregation inhibitors (disintegrins) from snake venoms are derived by proteolysis from a common precursor. Toxicon, 30: 265-293.

71. Moura-da-Silva AM, Theakston RDG \& Crampton JM (1996). Evolution of disintegrin cysteine-rich and mammalian matrix-degrading metalloproteinases: gene duplication and divergence of a common ancestor rather than convergent evolution. Journal of Molecular Evolution, 43: 263-269.

72. Scarborough RM, Rose JW, Naughton MA, Phillips DR, Nannizzi L, Arfsten A,
Campbell AM \& Charo IF (1993). Characterization of the integrin specificities of disintegrins isolated from American pit viper venoms. Journal of Biological Chemistry, 268: 1058-1065.

73. Paine MJI, Moura-da-Silva AM, Theakston RDG \& Crampton JM (1994). Cloning of metalloprotease genes in the carpet viper (Echis pyramidum leakeyi). Further members of the metalloprotease/disintegrin gene family. European Journal of Biochemistry, 224: 483-488.

74. Nishida S, Fujita $\mathrm{T}$, Atoda $\mathrm{H}$, Morita $\mathrm{T}$, Takeya H, Kido I, Paine MJI, Kawabata S \& Iwanaga S (1995). cDNA cloning and deduced amino acid sequence of prothrombin activator (Ecarin) from Kenyan Echis carinatus venom. Biochemistry, 34 : 1771-1778.

75. Takeya H, Nishida S, Nishino N, Makinose Y, Omori-Satoh T, Nikai T, Sugihara H \& Iwanaga $S$ (1993). Primary structures of platelet aggregation inhibitors (disintegrins) autoproteolytically released from snake venom hemorrhagic metalloproteinases and new fluorogenic peptide substrates for these enzymes. Journal of Biochemistry, 113: 473-483.

76. Wolfsberg TG, Primakoff $P$, Myles DG \& White JM (1995). ADAM, a novel family of membrane containing $\underline{A}$ Disintegrin And Metalloproteinase domain: multipotential functions in cell-cell and cell-matrix interactions. Journal of Cell Biology, 131: 275-278.

77. Blobel CP, Wolfsberg TG, Turck CW, Myles DG, Primakoff CW \& White JM (1992). A potential fusion peptide and an integrin ligand domain in a protein active in sperm-egg fusion. Nature, 356: 248252.

78. Almeida EAC, Huovilla APJ, Sutherland AE, Stephens LE, Calarco PG, Shaw LM, Mercurio AM, Sonnenberg A, Primakoff $P$, Myles DG \& White JM (1995). Mouse egg integrin $\alpha_{6} \beta_{1}$ functions as a sperm receptor. Cell, 81: 1095-1104.

79. Wolfsberg TG, Straight PD, Gerena RL, Huovila A-P, Primakoff $P$, Myles DG \& White JM (1995). ADAM, a widely distributed and developmentally regulated gene family encoding membrane proteins with
A Disintegrin And Metalloproteinase domain. Developmental Biology, 169: 378383.

80. Chantry A, Gregson N \& Glynn P (1989). A novel metalloproteinase associated with brain myelin membranes. Journal of Biological Chemistry, 264: 21603-21607.

81. Howard L, Lu X, Mitchell S, Griffiths S \& Glynn P (1996). Molecular cloning of MADMAM: a catalytically active mammalian disintegrin-metalloproteinase expressed in various cell types. Biochemical Journal, 317: 45-50.

82. Yagami-Hirosama T, Sato T, Kurisaki T, Kamijo K, Nabeshima Y \& Fujisawa-Sehara A (1995). A metalloproteinase-disintegrin participating in myoblast fusion. Nature, 377: 652-656.

83. Weskamp G, Kratzschmar J, Reid M \& Blobel CP (1996). MDC9, a widely expressed cellular disintegrin containing cytoplasmic SH3 ligand domains. Journal of Cell Biology, 132: 717-726.

84. Black RA, Rauch CT, Kozlosky CJ, Peschon JJ, Slack JL, Wolfson MF, Castner BJ, Stocking KL, Reddy P, Srinivasan $S$, Nelson N, Boiani $N$, Schooley KA, Gerhart M, Davis R, Fitzner JN, Johnson RS, Paxton RJ, March CJ \& Cerretti DP (1997). A metalloproteinase disintegrin that releases tumour-necrosis factor- $\alpha$ from cells. Nature, 385: 729-733.

85. Moss ML, Jin S-LC, Milla ME, Burkhart W, Cartner HL, Chen W-J, Clay WC, Didsbury JR, Hassier D, Hoffman CR, Kost TA, Lambert MH, Leesnitzer MA, McCauley $P$, McGeehan G, Mitchell J, Moyer M, Pahel G, Rocque W, Overton LK, Schoenen F, Seaton T, Su J-L, Warner J, Willard D \& Becherer JD (1997). Cloning of a disintegrin metalloproteinase that processes precursor tumour-necrosis factor- $\alpha$. Nature, 385: 733-736.

86. Moura-da-Silva AM, Laing GD, Paine MJI Dennison JMTJ, Politi V, Crampton JM \& Theakston RDG (1996). Processing of tumor-necrosis factor- $\alpha$ by venom metalloproteinases: a hypothesis explaining local tissue damage following snake bite. European Journal of Immunology, 26: 20002005 